\title{
Energy Reductions Using Next-Generation Remanufacturing Techniques
}

\author{
Final Technical Report \\ DOE Award No. DE-EE0003481 \\ Project Period: August 16, 2010 through November 30, 2011 \\ Issued Date: February 24, 2012 \\ Caterpillar Inc. \\ Product Development \& Global Technology \\ 14009 Old Galena Rd., TC-A \\ Mossville, IL 61552-7547 \\ Project Director: Dr. Daniel Sordelet, \\ Telephone: 309.578.5560, \\ E-mail: Sordelet Daniel@cat.com \\ Principal Investigator: Dr. Ondrej Racek, \\ Telephone: 309.578.9984, \\ E-mail: Racek Ondrej@cat.com
}




\section{Acknowledgment, Disclaimer and Document Availability}

This report is based upon work supported by the U. S. Department of Energy, Golden Field Office, under Award No. DE-EE0003481.

This report was prepared as an account of work sponsored by an agency of the United States Government. Neither the United States Government, nor any agency thereof, nor any of their employees, makes any warranty, express or implied, or assumes any legal liability or responsibility for the accuracy, completeness, or usefulness of any information, apparatus, product, or process disclosed, or represents that its use would not infringe privately owned rights. Reference herein to any specific commercial product, process, or service by trade name, trademark, manufacturer, or otherwise does not necessarily constitute or imply its endorsement, recommendation, or favoring by the United States Government or any agency thereof. Any findings, opinions, and conclusions or recommendations expressed in this report are those of the authors and do not necessarily reflect those of the United States Government or any agency thereof.

Reports are available free via the U.S. Department of Energy (DOE) Information Bridge Website: http://www.osti.gov/bridge

Reports are available to DOE employees, DOE contractors, Energy Technology Data Exchange (ETDE) representatives, and Informational Nuclear Information System (INIS) representatives from the following source:

Office of Scientific and Technical Information

P.O. Box 62

Oak Ridge, TN 37831

Tel: (865) 576-8401

FAX: (865) 576-5728

E-mail: reports@osti.gov

Website: http://www.osti.gov/contract.html 
TABLE OF CONTENTS

1. Executive Summary

2. Introduction

3. Background

4. Results and Discussion

4.1 Task 1

4.2 Tasks 2 and 3

4.2.1 Fe-based Substrates

4.2.2 Al-based Substrates

5. Benefits Assessment

6. Commercialization

7. Accomplishments

8. Conclusions

\section{Page Number}

4

6

7

12

12

15

15

24

26

29

29

30

\section{LIST OF ACRONYMS}

High-velocity Oxygen fuel spraying (HVOF)

Laser-assisted High-velocity Oxygen fuel spraying (LAHVOF)

Twin-wire arc spraying (TWA)

Laser-assisted Twin-wire arc spraying (LATWA)

\section{LIST OF FIGURES}

Figure 1. (a) generic thermal spray process showing heated or molten particles accelerated from the spray device towards the substrate where they impact, flatten, quickly cool and build up to form a coating. (b) cartoon illustrating the architecture of a typical thermal spray coating showing the lamellar-type microstructure and, in particular the roughened substrate surface that is obtained typically by grit blasting.

Figure 2. Typical microstructure of a thermal spray coating (top) on a grit-blasted steel substrate (bottom). Delamination of coating is visible along with residual embedded $\mathrm{Al}_{2} \mathrm{O}_{3}$ grit particle (arrow), which hinders successful post-spray grinding.

Figure 3. (a) schematic representation of LAHVOF process illustrating how laser strikes and heats substrate in front of incoming hot powder particles from HVOF torch. Critical variables in this process include traverse speed of laser and torch, laser powder ( $\mathrm{kW})$, HVOF spray velocity (v), distance between 
laser and torch $(d)$ and stand-off distance between torch and substrate; (b) top photo shows laser coupled with an HVOF torch in front of a cylinder to be coated by the LAHVOF technique, while bottoms shows LAHVOF process in action as the cylinder rotates clockwise: upper bright spot is laser heating the surface just before the HVOF spray impacts the surface (lower bright spot) and (c) microstructure of LA-HVOF WC-Co coating showing intimate, metallurgical bond between the coating and the 316 SS substrate.

Figure 4. Photographs of standard HVOF (i.e., grit blasted substrate) and LA-HVOF coated steel substrates after 100,000 fatigue cycles. Delamination of the coating occurs due to the weaker mechanical bond from grit blasting, while the laser-assisted coating shows no indication of cracking or delamination.

Figure 5. (a) Photograph of experimental LATWA setup showing conventional TWA spray torch sitting adjacent to laser head; both are mounted to a fixture that is attached to a multi-axis robot that moves the two in concert at controlled traverse speeds and (b) schematic cartoon displaying the orientation of the TWA torch and laser head and illustrating the critical LATWA processing parameters of laser stand-off distance, separation length between TWA spray particles and laser beam $(d)$ and laser stand-off distance.

Figure 6. Gray oxide inclusions within conventional TWA coatings deposited using (a) air and (b) nitrogen.

Figure 7. Relative laser power density (as displayed on thermally-sensitive paper) as a function of laser standoff distance (mm). Focal distance of $320 \mathrm{~mm}$ yields the smallest laser "foot print", which corresponds to the higher power density for surface heating.

Figure 8. The effect of laser standoff distance and traverse speed on adhesion of LATWA1020 steel coatings.

Figure 9. Polished cross sections of a LATWA coating where (a) the laser was run for the first few passes (area A) and then turned off for the remaining TWA deposition (area B), (b) high-magnification image of the substrate/coating interface and (c) interface after etching.

Figure 10. Shrouding techniques used to help protect TWA spray particles from oxidation during spraying: (a) sheet metal shroud with through hole for laser beam and (b) air-amplifier outside of path of laser.

Figure 11. Polished cross sections of a LATWA coatings from (a) Run 3 and (b) Run 5 described in Table 3.

Figure 12. Polished cross sections of a LATWA coatings from (a) Run 1 and (b) Run 2 described in Table 3. 
Figure 13. Adhesion strengths of selected LATWA coatings compared to typical value from conventional TWA coatings sprayed using nitrogen.

Figure 14. Polished cross sections of 1080 steel LATWA coatings from (a) Run 6 and (b) Run 7 described in Table 3.

Figure 15. Polished cross sections of a 420 SS LATWA coating using a $290 \mathrm{~mm}$ standoff distance, $200 \mathrm{~mm} / \mathrm{s}$ traverse speed and $d-10 \mathrm{~mm}$.

Figure 16. Polished cross sections of through-thickness laser-treated LATWA coatings prepared using (a) shroud shown in Figure 10a and (b) no shroud.

Figure 17. Vickers hardness data from conventional TWA and through-thickness lasertreated LATWA coatings, both using 1020 steel.

Figure 18. Dimensions of the four point bending fixture and bar specimen

Figure 19. Fatigue life of steel bar specimens compared to internal data from prior work, as identified by 2005-2006 time periods.

Figure 20. Fatigue life of cast iron specimens.

Figure 21. Cut sections from the failed fatigue tested bars, (a) fracture surface, (b) surface close to the fracture

Figure 22. Microstructures of the cast iron bars, (a) in the case and (b) in the core

Figure 23. Hardness through the cross section of the cast iron bars.

Figure 24.. Etched cross section of the LATWA coated steel bar.

Figure 25. Etched cross section of the conventional TWA coated steel bar.

Figure 26. Etched cross section of the LATWA coated cast iron bar.

Figure 27. Polished cross sections of LATWA coatings on 2024 Al using (a) low heat input and (b) high heat input conditions. Images on the the right on magnified views of the areas in the red dash lines. 


\section{EXECUTIVE SUMMARY}

The goal of this project was to develop a radically new surface coating approach that greatly enhances the performance of thermal spray coatings. Rather than relying on a roughened grit blasted substrate surface for developing a mechanical bond between the coating and substrate, which is the normal practice with conventional thermal spraying, a hybrid approach of combining a focused laser beam to thermally treat the substrate surface in the vicinity of the rapidly approaching thermally-sprayed powder particles was developed. This new surface coating process is targeted primarily at enabling remanufacturing of components used in engines, drive trains and undercarriage systems; thereby providing a substantial global opportunity for increasing the magnitude and breadth of parts that are remanufactured through their life cycle, as opposed to simply being replaced by new components. The projected benefits of a new remanufacturing process that increases the quantity of components that are salvaged and reused compared to being fabricated from raw materials will clearly vary based on the specific industry and range of candidate components that are considered. At the outset of this project two different metal processing routes were considered, castings and forgings, and the prototypical components for each process were liners and crankshafts, respectively. The quantities of parts used in the analysis are based on our internal production of approximately 158,000 diesel engines in 2007. This leads to roughly 1,000,000 liners (assuming a mixture of 6- and 8-cylinder engines) and 158,000 crankshafts. Using energy intensity factors for casting and forgings, respectively, of 4450 and $5970 \mathrm{Btu}-\mathrm{hr} / \mathrm{lb}$ along with the energy-induced $\mathrm{CO}_{2}$ generation factor of $3.8 \times 10^{-4} \mathrm{lbs} \mathrm{CO}_{2} / \mathrm{Btu}$, energy savings of over $17 \times 10^{12}$ BTUs and $\mathrm{CO}_{2}$ reductions of over $6.5 \times 10^{6}$ lbs could potentially be realized by remanufacturing the abovementioned quantities of crankshafts and liners.

This project supported the Industrial Technologies Program's initiative titled "Industrial Energy Efficiency Grand Challenge.” To contribute to this Grand Challenge, we. pursued an innovative processing approach for the next generation of thermal spray coatings to capture substantial energy savings and green house gas emission reductions through the remanufacturing of steel and aluminum-based components. The primary goal was to develop a new thermal spray coating process that yields significantly enhanced bond strength. To reach the goal of higher coating bond strength, a laser was coupled with a traditional twin-wire arc (TWA) spray gun to treat the component surface (i.e., heat or partially melt) during deposition. Both ferrous and aluminum-based substrates and coating alloys were examined to determine what materials are more suitable for the laserassisted twin-wire arc coating technique. Coating adhesion was measured by static tensile and dynamic fatigue techniques, and the results helped to guide the identification of appropriate remanufacturing opportunities that will now be viable due to the increased bond strength of the laser-assisted twin-wire arc coatings.

The feasibility of the laser-assisted TWA (LATWA) process was successfully demonstrated in this current effort. Critical processing parameters were identified, and when these were properly controlled, a strong, diffusion bond was developed between the substrate and the deposited coating. Consequently, bond strengths were nearly doubled over those typically obtained using conventional grit-blast TWA coatings. Note, 
however, that successful LATWA processing was limited to ferrous substrates coated with steel coatings (e.g., 1020 and 1080 steel). With Al-based substrates, it was not possible to avoid melting a thin layer of the substrate during spraying, and this layer resolidified to form a band of intermetallic phases at the substrate/coating interface, which significantly diminished the coating adhesion.

The capability to significantly increase the bond strength with ferrous substrates and coatings may open new remanufacturing opportunities that were previously not considered due to concerns with the limits of the mechanical bonding of conventional TWA coatings. However, the limited results obtained within this one-year program are not sufficient to move the LATWA into a production environment. Additional work will be needed engineer the process to coat components with more complex geometries than the flat specimens studied in this work. In addition part-specific bench testing and relevant field tests will be required to fully establish the necessary confidence for introducing the LATWA process. These are typical constraints and requirements for most any new production process, and it is quite possible this new process will continue to be a viable approach for extending the usage of remanufacturing, and in turn capturing the resulting energy savings and green house gas emission reductions. 


\section{INTRODUCTION}

Our effort to develop a new surface coating approach was targeted primarily at enabling remanufacturing of components used in engines, drive trains and undercarriage systems. These components are vital to industrial machines and engines operating in construction, road-building, mining, forestry, energy, transportation and material-handling industries. Many of these machines, which range from track-type tractors (bulldozers) to hydraulic excavators, backhoe loaders, motor graders, off-highway trucks, wheel loaders, and agricultural tractors, are comprised mainly of steel, but also include a growing portion of aluminum alloys. In addition, our remanufacturing business provides it refurbishing services to a wide range of outside customers (e.g., Ford and Landrover), significantly increasing the potential impact component restoration. Although we are a major remanufacturer, there is a substantial global opportunity for other industries (e.g., aerospace, rail, marine, defense) for increasing the magnitude and breadth of parts that are remanufactured through their life cycle, as opposed to simply being replaced by new components. As discussed in more detail in Chapter 5 , the benefits of this opportunity are quite clear: tremendous energy savings and green house gas (GHG) emission reductions. For example, even if only engine cylinder liners and crankshafts are considered over the course of one year, over 17 trillion Btu's may potentially be saved while at the same time reducing $\mathrm{CO}_{2}$ emissions by over 6 million lbs; estimates are based on 2007 our internal production of 158.000 diesel engines. Moreover, the energy saving and GHG emission benefits come with easily documentable cost savings.

The process developed during this project is referred to a Laser-assisted Twin-wire Arc (LATWA) spraying. It is a hybrid coating approach that combines a high-power laser with a conventional twin-wire arc (TWA) thermal spray torch, constituting a radically new approach that will (i) greatly enhance the performance of thermal spray coatings, providing greater opportunities for energy and GHG reductions, and (ii) eliminate the costly, environmentally unfriendly grit blasting process step. Rather than relying on a roughened grit blasted substrate surface for developing a mechanical bond between the coating and substrate, which is the case for TWA spraying, a hybrid approach of combining a focused laser beam to thermally treat the substrate surface immediately in front of the rapidly approaching thermally-sprayed powder particles has been developed. This approach can form a fully dense, very strong metallurgical bond between the substrate and the coating (i.e., diffusion between the coating and adjacent substrate). As a consequence, an extremely wide variety of thermal spray coatings are viable for energysaving applications, particularly remanufacturing opportunities where, until now, they were not desired options due to failures arising primarily from the weak mechanical bond at the coating/substrate interface. 


\section{BACKGROUND}

Brief background of thermal spray coatings:

Thermal spray coatings comprise a collective group of surface treatment processes that vary by the heat source used to heat the coating material (e.g., oxygen-fuel combustion, dc plasma arc) and by the form of the coating material as it enters the heat source (e.g., powder or wire). The more common thermal spray techniques are flame spraying, twinwire arc spraying, plasma arc spraying and high-velocity oxygen-fuel (HVOF) spraying. Figure 1a shows a cartoon of a generic thermal spray process where the feed stock material is heated and accelerated from the spray device as hot, sometimes molten particles that impact the substrate, rapidly cool and build up to form a coating. The general architecture of a thermal spray coating is portrayed in Figure 1b, which reveals the lamella-type structure that develops as incoming particles strike the surface and flatten out to form "splats". Also shown in Figure 1b is the roughened substrate surface. This roughness is most often obtained through grit blasting using hard, angular particles like $\mathrm{Al}_{2} \mathrm{O}_{3}$ or $\mathrm{SiC}$. The purpose of grit blasting is to form this tortuous surface topography so that the initial incoming hot particles can strike the surface and conform to the peaks and valleys, gripping to these features and thereby forming a mechanical bond that serves as the mechanism to hold to coating onto the substrate.
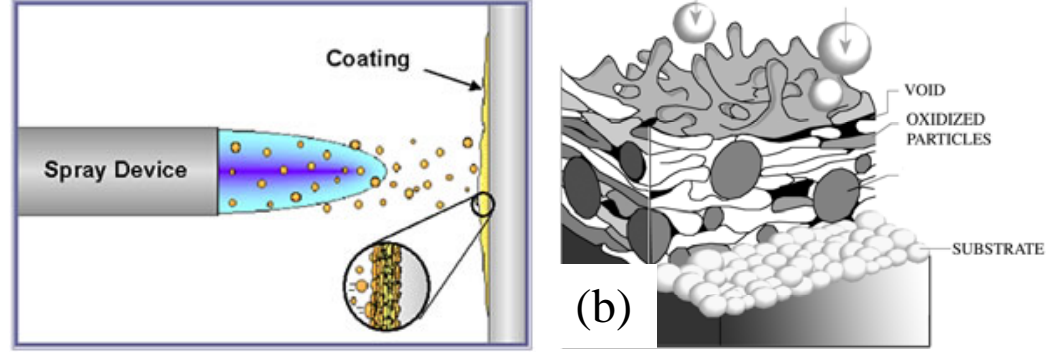

Figure 1. (a) generic thermal spray process showing heated or molten particles accelerated from the spray device towards the substrate where they impact, flatten, quickly cool and build up to form a coating. (b) cartoon illustrating the architecture of a typical thermal spray coating showing the lamellar-type microstructure and, in particular the roughened substrate surface that is obtained typically by grit blasting.

Regardless of the specific process, all thermal spray coatings have limited bond strength due to their mechanical bond with the substrate. Figure 2 displays a typical state-of-the-art HVOF coating microstructure illustrating the common defects (e.g., embedded grit particles and coating delamination) that can occur at the interface with the substrate. Coatings prepared by other thermal spray methods such as plasma arc and wire arc spraying have somewhat different microstructures, but nevertheless have interfaces with their substrates that are similar to the one shown in Figure 2, and as a result share the same undesirable limitation of adhering to the substrate only through the means of a mechanical bond. Two secondary, but certainly non-trivial consequences

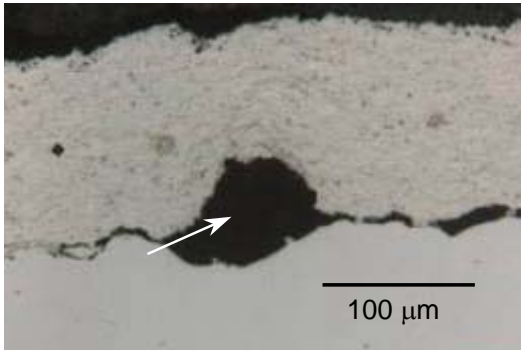

Figure 2. Typical microstructure of a thermal spray coating (top) on a gritblasted steel substrate (bottom). Delamination of coating is visible along with residual embedded $\mathrm{Al}_{2} \mathrm{O}_{3}$ grit particle (arrow), which hinders successful post-spray grinding. of using grit blasting to treat the surface of a material are the equipment and disposal costs. The former can approach $\$ 1 \mathrm{M}$ for dedicated, robotically-controlled blasting 
booths, while the latter is often exacerbated when materials containing $\mathrm{Cr}$ and $\mathrm{Ni}$, which are ubiquitous in thermal spray coatings, are used, thereby rendering the exhausted grit as a potential hazardous material. Clearly there are performance-, cost- and environmentalbased incentives for replacing the current grit blasting surface preparation used to secure a bond between a thermal spray coating and an underlying substrate. The approach pursued in this proposed effort is described below.

The general processing approach for laser-assisted thermal spraying is illustrated in Figure 3a, which shows the laser beam striking the substrate in front of the incoming

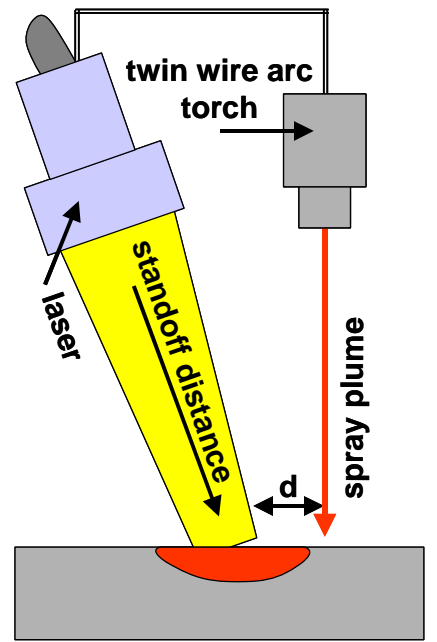

traverse speed (a)

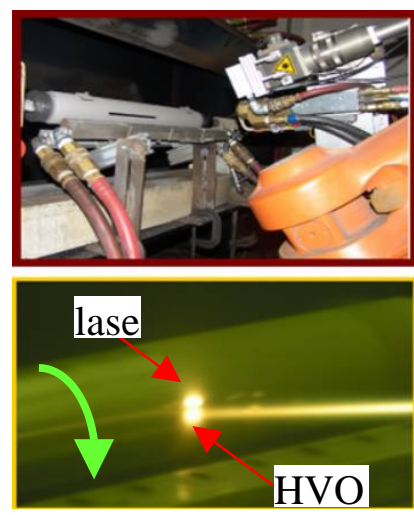

(b)

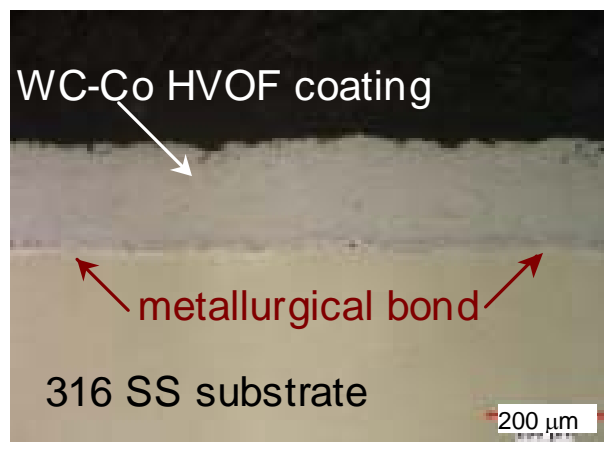

(c)

Figure 3. (a) schematic representation of LAHVOF process illustrating how laser strikes and heats substrate in front of incoming hot powder particles from HVOF torch. Critical variables in this process include traverse speed of laser and torch, laser powder (kW), HVOF spray velocity (v), distance between laser and torch $(d)$ and stand-off distance between torch and substrate; (b) top photo shows laser coupled with an HVOF torch in front of a cylinder to be coated by the LAHVOF technique, while bottoms shows LAHVOF process in action as the cylinder rotates clockwise: upper bright spot is laser heating the surface just before the HVOF spray impacts the surface (lower bright spot) and (c) microstructure of LA-HVOF WC-Co coating showing intimate, metallurgical bond between the coating and the 316 SS substrate.

spray plume of hot powders coming from a twin wire arc spray torch, in this example. The laser and torch are moving from right to left, therefore the substrate surface is heated/melted immediately before the hot particles strike the surface, allowing for rapid diffusion between the substrate surface and the developing coating. An actual example of the metallurgical bond that can form is shown in Figure 3c, where a WC-Co coating has been deposited onto a 316 stainless steel substrate using laser-assisted HVOF (LAHVOF) spraying. The thin white region marked by the red arrows is the metallurgical bond that formed. Remarkably, even the WC particles, which melt at $2870{ }^{\circ} \mathrm{C}$, were fused in the presence of the laser and incorporated into this strong, uniform bond layer. Comparing this interface to one in Figure 2 clearly reveals the improved bonding that is accessible with incorporating a laser into the conventional thermal spray process. The laser-assist thermal spray technique has some obvious similarities to the laser cladding surface treatment process. However, traditional laser cladding has much lower deposition rates, leading to higher processing costs. Also, laser cladding induces more surface heating, 
which can create a deeper heat affected zone in the substrate (e.g., up to $500 \mu \mathrm{m}$ as compared to 20-100 $\mu \mathrm{m}$ for LA-HVOF) and seriously degrade mechanical properties.

The feasibility of the laser-assisted thermal spray process was demonstrated within our Technical Center using high-velocity oxygen-fuel (HVOF) spraying within the framework of the DOE-supported program, "Structurally Integrated Coatings for Wear and Corrosion”, DE-FC36-04GO14037 between 2006-2008. Subsequently, a limited amount of additional developmental work was focused on depositing wear-resistant coatings for track-type tractors and evaluated during extended field tests. These initial laser-assisted HVOF (LAHVOF) efforts helped to differentiate the bonding type and performance issues between the laser-assisted process and the conventional grit blasting approach. For example, Figure 4 displays the results of two fatigue tests with $\mathrm{Cr}_{2} \mathrm{C}_{3}-$ based HVOF coatings on steel substrates run to 100,000 cycles at the same stress. On the left is the conventionally sprayed HVOF coating (i.e., grit blasted) showing significant delamination and spallation of the coating. Conversely the laser-assisted HVOF coating deposited onto the substrate shown on the right exhibits no evidence of cracking or delamination. Ultrasonic inspection of these samples further supported the visual evidence that the laserassisted coating is indeed more strongly adhered to the substrate than the conventional one deposited
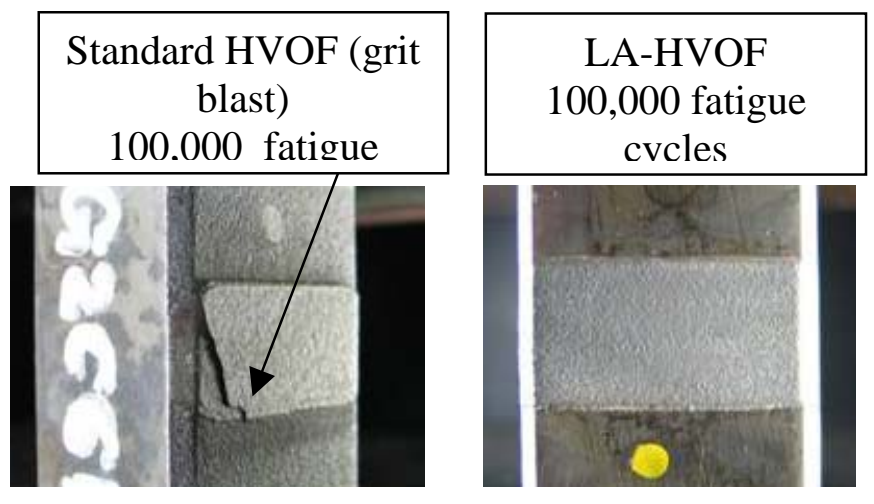

Figure 4. Photographs of standard HVOF (i.e., grit blasted substrate) and LA-HVOF coated steel substrates after 100,000 fatigue cycles. Delamination of the coating occurs due to the weaker mechanical bond from grit blasting, while the laser-assisted coating shows no indication of cracking or delamination.

onto a typical grit blasted substrate. To date, our internal developments have focused on HVOF spraying for improved wear and corrosion resistance. It is far more straightforward to consider coupling a laser with this spraying process because the "footprint" of the incoming particles in an HVOF spray plume is around $5 \mathrm{~mm}$, which conforms well to a typical spot size from a high-power laser. While HVOF is a widely used thermal spray technique for enhancing the performance of a material, there are other thermal spray techniques, in particular twin wire arc spraying that are far more economical from both equipment and raw material (wire is used rather than powder) viewpoints, which make them preferred candidates for a wider range of remanufacturing operations due to lower operating and starting material costs.

All the coating development work for the current project was performed in the Thermal Spray Laboratory at our Technical Center. Primarily Dr. Ondrej Racek, who has pioneered the technique of coupling lasers with thermal spray systems to yield advanced coating structures, performed the research. Moreover, Dr. Racek has expertise in the characterization and testing of coatings, which were instrumental in successfully identifying and controlling the critical processing parameters for the LATWA process. 
Other personnel involved in this work have a long, successful history of working together with DOE to support different materials- and processes-related missions. In particular, Dr. M. Brad Beardsley has directed 5 programs, most recently one titled "Structurally Integrated Coatings for Wear and Corrosion”, DE-FC36-04GO14037, during which the feasibility of the laser-assisted thermal spray process for heavy machinery was established using the HVOF technique. This work is being pursued further as part of the manufacturing process for undercarriage components. In early 2009, Dr. Daniel Sordelet joined the Technical Center following 20 years at the DOE Ames National Laboratory and Iowa State University. Throughout his work there, Sordelet was involved in numerous surface coating development studies sponsored by DOE, DOD and numerous industrial partners, and has successfully developed intellectual property portfolios involving surface coatings that have been licensed by industry and are approaching production.

The three primary technical objectives for this one-year development effort are described below. Results from these tasks as they pertain to the overall program goals are discussed in more detail in Chapter 4.

1. Design and demonstrate processing capability for the LATWA spraying technique to deposit coatings that have a strong, metallurgical bond with their underlying substrate and minimize the depth of the heat affected zone within the substrate. This will also help establish what coating and substrate materials are viable partners for this process, allowing for more intelligent targeting of specific remanufacturing opportunities.

2. Define the accessible processing space to discern the size of a surface that can be successfully coated at a particular deposition rate (described in mass of coating/unit time) and what coating thickness can be achieved before the delamination from the surface initiates. These will most certainly be dependent on the type of coating and substrate materials, so this task will be defined with input from the objective above in order to avoid surveying materials that are unlikely to be used with the LATWA process.

3. Quantify the improvement in coating adhesion with a metallurgical bond as compared to the conventional mechanical bond. This will be performed primarily using tensile testing of as-coated samples. Additonally highcycle fatigue testing will complement the coating adhesion tests to provide additional qualitative comparisons between LATWA and conventional thermal spray coatings, as well as to identify what LATWA parameters most strongly influence bond strength. 


\section{RESULTS AND DISCUSSION}

The technical effort of this program was performed throughout the following three tasks:

1. Develop and demonstrate feasibility of Laser-assisted Twin-Wire Arc (LA-TWA) coatings

2. Define processing capabilities and limitations for LA-TWA with selected materials

3. Quantify coating adhesion differences between LA- and conventional TWA processes.

In the following discussion Tasks 2 and 3 are combined for clarity. Also, the work performed on Fe- and Al-based substrates is described separately.

\subsection{Task 1:}

The actual experimental equipment used for the LATWA process is shown in Figure 5 along a cartoon representing the spatial relationship between the TWA torch and the laser. As described earlier in Section 3, the LATWA process involves having the laser impact the substrate surface in advance of the molten droplets streaming from the TWA torch. This is depicted in Figure 5b, and in this orientation the LATWA process would be moving from the right to the left so that the TWA particles are landing on the substrate surface that has been heated/melted by the laser. Similarly, if the substrate was round and was being rotated during coating, it would be moving clockwise in order for the surface to be treated by the laser before coming under the spray of particles from the TWA torch.
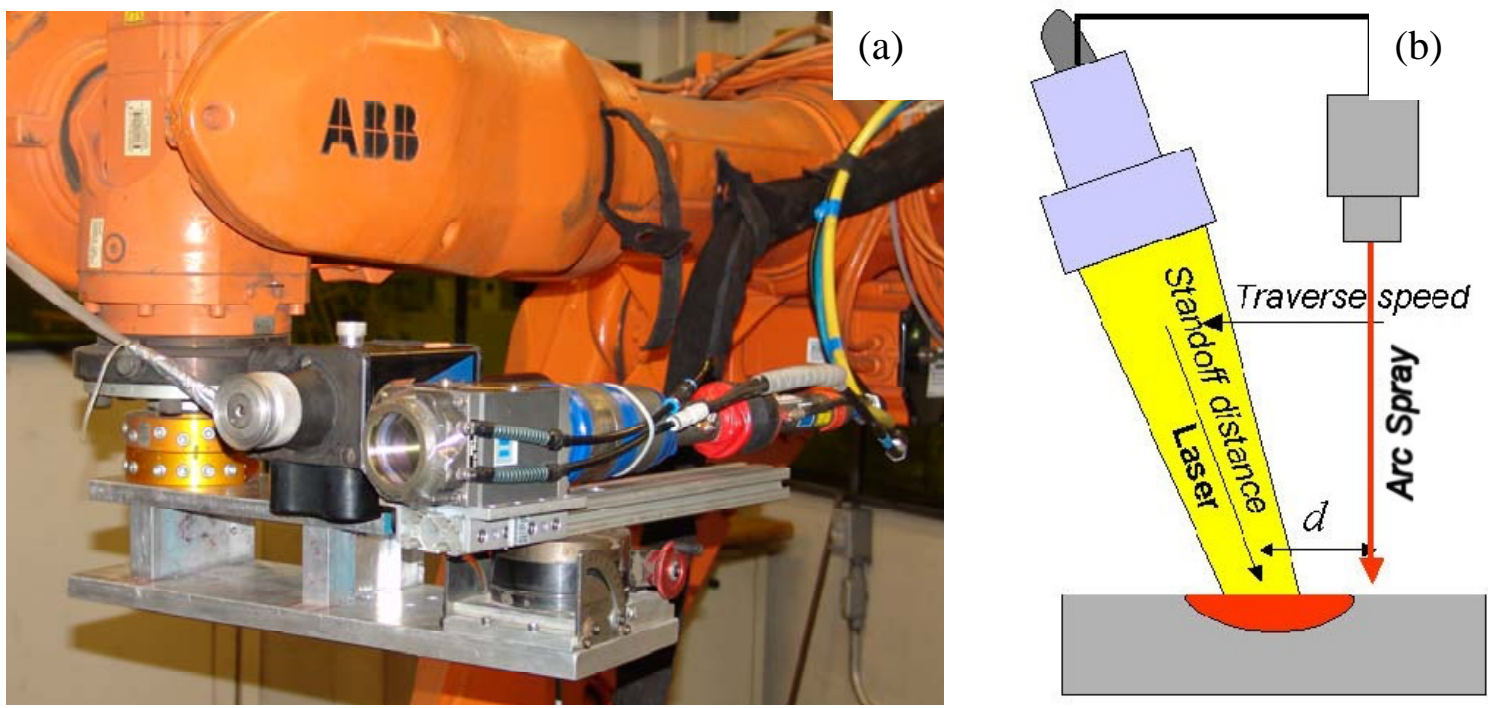

Figure 5. (a) Photograph of experimental LATWA setup showing conventional TWA spray torch sitting adjacent to laser head; both are mounted to a fixture that is attached to a multi-axis robot that moves the two in concert at controlled traverse speeds and (b) schematic cartoon displaying the orientation of the TWA torch and laser head and illustrating the critical LATWA processing parameters of laser stand-off distance, separation length between TWA spray particles and laser beam $(d)$ and laser stand-off distance. 
The primary objective of this task was to survey a wide range of processing parameters to determine the feasibility of the LATWA process using steel wire and Fe-based substrates. At the outset of the project, coating oxidation was a serious concern since the presence of oxides would likely inhibit forming good adhesion both between the coating and substrate and between particles within the bulk of the coating. During the normal TWA process, high-pressure ( $60-100 \mathrm{psi})$ gas is used to accelerate the molten metal droplets that form in the arc between the two wires. Compressed air is typically used, but we found that using nitrogen helped reduce the amount of oxidation within the resulting coating. For example, Figure 6 shows polished cross sections of 1020 steel coatings sprayed with air and nitrogen; the former clearly yield more oxide particles within the coating, as illustrated by the darker gray splat boundaries. Consequently, nitrogen was used as the primary atomizing gas in all the coating trials performed throughout this project.

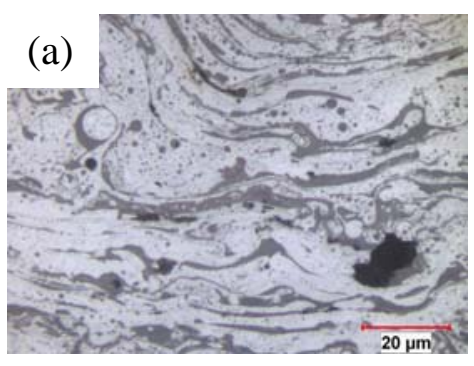

(b)

Figure 6. Gray oxide inclusions within conventional TWA coatings deposited using (a) air and (b) nitrogen.

There are a large number of parameters that affect coating structure and properties, particularly for the hybrid LATWA process. Table 1 displays some of the critical parameters and the characteristics they primarily control. The TWA parameters were fixed throughout the spraying experiments ( 180 amps, 42 volts and 60 psi gas pressures). The bottom three laser-related parameters in Table 1 were found to be particularly influential in controlling coating quality. The parameters are also illustrated in Figure 5b. Specifically, the traverse speed refers to the velocity of the robot arm that is moving both the TWA torch and the laser head, Figure 5a. Lower speeds can lead to increased time for the laser-treated surface to oxidize before the TWA particles arrive. The laser stand-off distance controls the power density as the laser beam strikes the substrate surface. This is because at a stand-off distance longer or shorter than the focal length, the power density will be less. This can be visualized by looking at the laser footprints that were obtained by directing the laser onto "burn paper" at different distances. The focal length for our laser is $320 \mathrm{~mm}$, and Figure 7 shows that the laser has the smallest footprint (i.e., highest power density) at this standoff distance. Moving to shorter stand-off distances decreases the power density and the degree of substrate heating/melting. The combined effects of the robot traverse speed and the laser stand-off distance are visible in Figure 8, which shows much more surface/coating melting at higher laser power density $(320 \mathrm{~mm}$ stand-off

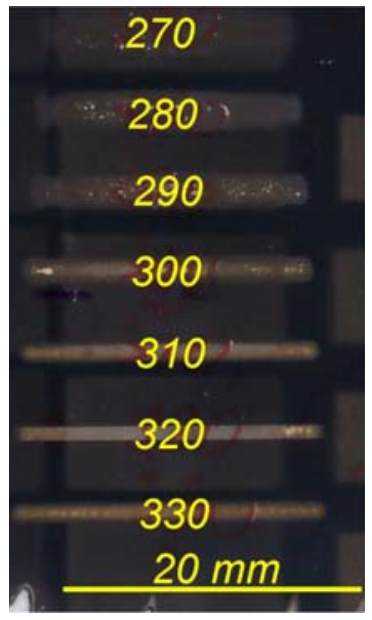

Figure 7. Relative laser power density (as displayed on thermallysensitive paper) as a function of laser standoff distance (mm). Focal distance of 320 $\mathrm{mm}$ yields the smallest laser "foot print", which corresponds to the higher power density for surface heating. 
distance) along with deeper substrate heat-affected zone at slower robot traverse speeds. Lastly, the laser spot-spray distance (d) describes the space between where the laser spot and TWA particles impact the substrate, as illustrated in Figure 5b. At $d=0$, the laser spot and TWA particles impact the same substrate location. Extending $d$ values increases the distance between the two points of impact, and at a fixed robot traverse speed this increases the time between laser and TWA spray impact.

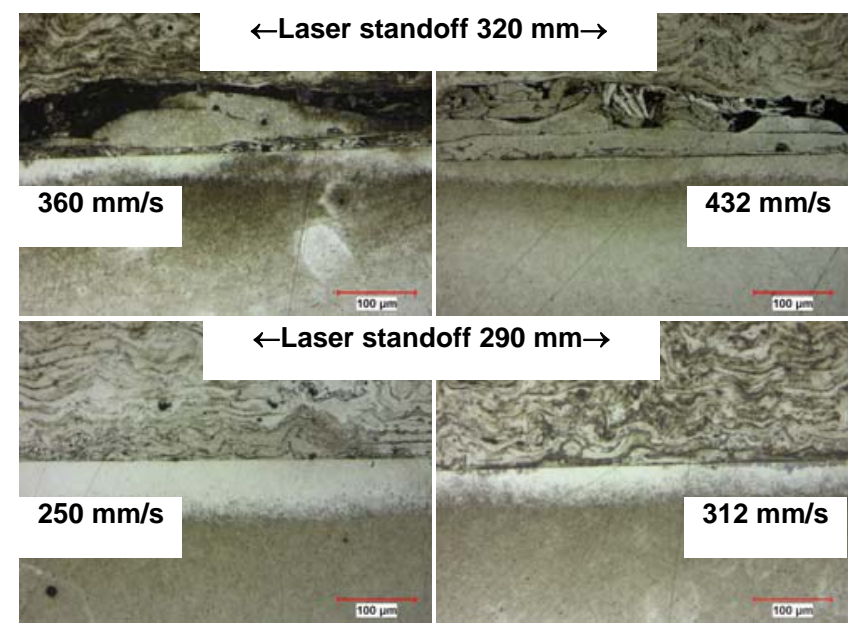

Figure 8. The effect of laser stand-off distance and traverse speed on adhesion of LATWA1020 steel roatings.

A large number of coating trials were run with variations to the bottom three parameters in Table 1. A process window was defined for the initial 1020 steel wire and 4140 substrates, and the feasibility of the LATWA process was demonstrated by the appropriate selection of laser-based parameters. For example, Figure 9a shows the polished cross section of a LATWA coating where the laser was run for the first few passes (area A) and then turned off for the remaining TWA deposition (area B). The desired diffusional bonding between the substrate and coating may be see in Figures 9b, which is a high-magnification view of substrate/coating interface; moreover, this interface after etching, Figure 9c, reveals on continuum between the two materials, further showing evidence of diffusion between the substrate and LATWA coating.

Table 1. Critical characteristics and operating parameters LATWA process

\begin{tabular}{|l|l|l|}
\hline Key characteristic & Process parameter & Equipment \\
\hline Enthalpy for feedstock melting & Current/Voltage & TWA \\
\hline Molten feedstock atomization & $\mathrm{N}_{2}$ primary gas pressure & TWA \\
\hline Spray shielding/constriction & $\mathrm{N}_{2}$ secondary gas pressure & TWA \\
\hline Exposure time \& layer thickness & Traverse speed & Robot \\
\hline Laser power density & Laser stand-off distance & Laser \\
\hline $\begin{array}{l}\text { Time between the laser heating and } \\
\text { spray droplet impact }\end{array}$ & Laser spot-spray distance (d)/traverse speed & Robot \\
\hline
\end{tabular}

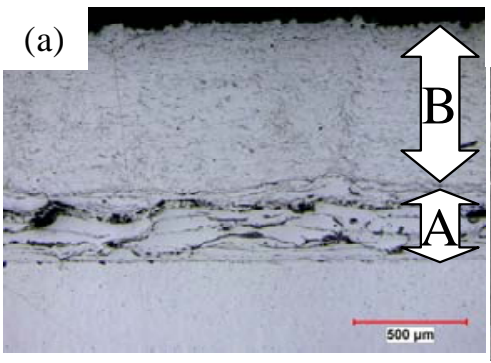

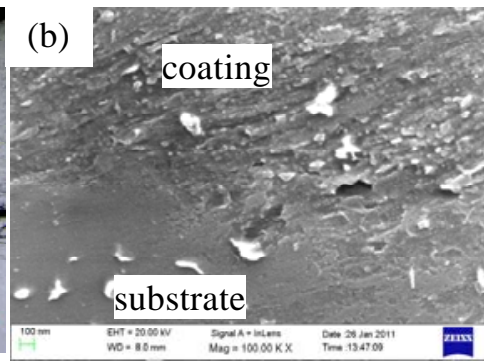

(c) coating

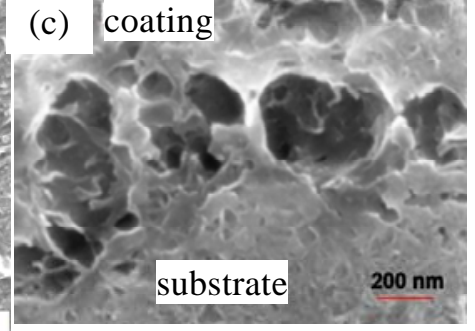

Figure 9. Polished cross sections of a LATWA coating where (a) the laser was run for the first few passes (area A) and then turned off for the remaining TWA deposition (area B), (b) highmagnification image of the substrate/coating interface and (c) interface after etching. 
Despite the successful development of a diffusion bond, Figure 9a shows the severe tendency for oxidation during LATWA process (dark regions within area A are oxides). A variety of process parameter changes together with different shrouding techniques were examined to reduce the level of oxides at the substrate/coating interface and within the coating. The methods and results are discussed in the following section.

\subsection{Tasks 2 and 3:}

\subsubsection{Fe-based Substrates.}

Several shrouding configurations were used to try and flood the environment around the LATWA process. The two primary arrangements are described in Figure 10. In one arrangement, a metal cone was fabricated to completely surround the laser beam and TWA spray plume with a moderate flow of nitrogen, Figure 10a. A hole was made in the cone to allow for the laser beam to pass through during the LATWA process. In the second arrangement, a commercial air amplifier, Figure 10b, was used that allows for an annular feed of a secondary protective gas, which was nitrogen in our experiments, to flow and surround the TWA spray; in this arrangement, the laser beam path was outside the shroud. A series of 1020 coatings were prepared and subsequently removed from their substrates for analysis of oxygen (inert gas fusion technique) and carbon (combustion chromatography technique). For an additional comparison, samples sprayed without a shroud were analyzed to measure the effect of atomizing gas on oxidation and decarburization. The results displayed in Table 2 clearly show that atomizing gas has a pronounced effect on oxidation and carbon loss, while the two shrouding arrangements only yielded subtle decreases in the degree of oxidation compared to the unshrouded sample prepared with nitrogen as the atomizing gas. As a consequence, no shrouding was used in the remaining coating experiments.

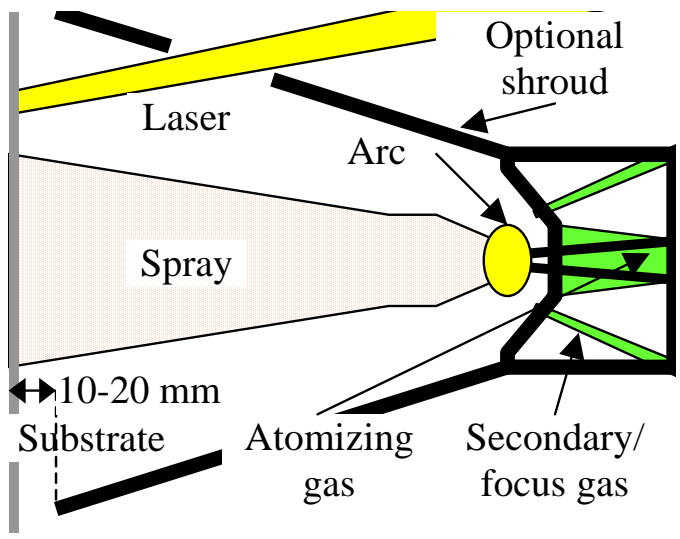

(a)

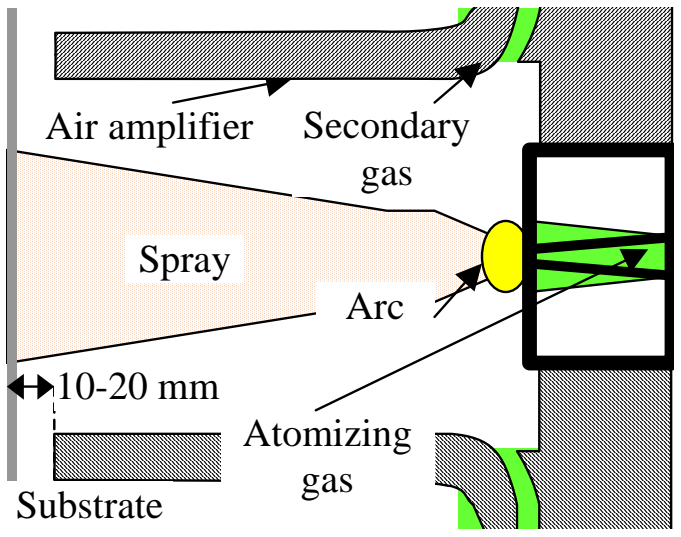

(b)

Figure 10. Shrouding techniques used to help protect TWA spray particles from oxidation during spraying: (a) sheet metal shroud with through hole for laser beam and (b) air-amplifier outside of path of laser.

After analyzing the results from a large number of coating runs that surveyed a broad range of laser-based parameters, the small number of experiments listed in Table 3 were performed to determine more optimal parameters for the 1020 steel coatings on 4140 
steel substrates. Even though the conditions in Table 3 do not differ significantly; the resulting coatings show strongly contrasting structures and substrate interfaces. The coating adhesion was highly sensitive to the laser stand-off distance. The focal plane distance was about $320 \mathrm{~mm}$, therefore, decreasing the standoff distance moved the substrate out of focus, which resulted in lower laser power density. At the higher laser power density (310 mm stand-off distance), the coatings from Runs 3 and 5 were either completely delaminated or severely oxidized, Figure 11. By reducing the stand-off distance to $290 \mathrm{~mm}$ (Runs 1 and 2), no delamination or coating oxidation was apparent on the polished cross-sections, Figure 12.

Table 2. Oxygen and carbon analyses of 1020 steel TWA coatings sprayed with air and nitrogen

\begin{tabular}{|c|c|c|c|c|}
\hline Element & Air atomizing gas & \multicolumn{3}{|c|}{$\mathbf{N}_{\mathbf{2}}$ atomizing gas } \\
\hline wt\% & no shroud & no shroud & Cone & Amplifier \\
\hline Oxygen & 7.72 & 1.54 & 0.846 & 1.17 \\
\hline Carbon & 0.028 & 0.097 & 0.095 & 0.076 \\
\hline
\end{tabular}

Table 1. Design of experiments for LATWA coatings using 1020 and 1080 steel

\begin{tabular}{|c|c|c|c|c|}
\hline Run \# & Coating Material & $\begin{array}{c}\text { Stand-off } \\
\text { distance }(\mathrm{mm})\end{array}$ & $\begin{array}{c}\text { Speed } \\
(\mathrm{mm} / \mathrm{s})\end{array}$ & $\begin{array}{c}\text { Laser-Spray } \\
d(\mathrm{~mm})\end{array}$ \\
\hline 1 & low C steel & 290 & 200 & 10 \\
\hline 2 & low C steel & 290 & 160 & 5 \\
\hline 3 & low C steel & 310 & 200 & 5 \\
\hline 4 & low C steel & 310 & 160 & 10 \\
\hline 5 & low C steel & 290 & 160 & 10 \\
\hline 6 & high C steel & 290 & 200 & 10 \\
\hline 7 & high C steel & 290 & 200 & 5 \\
\hline
\end{tabular}

The adhesion of the coatings parallels the microstructural variations shown in Figures 11 and 12. To measure the bond strength of the different TWA and LATWA coatings, 25 $\mathrm{mm}$ diameter steel buttons were sprayed. Afterwards, the coated buttons were glued to

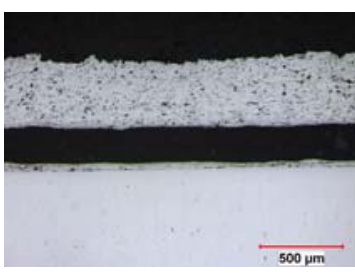

(b)

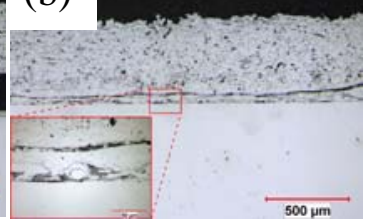

Figure 11. Polished cross sections of LATWA coatings from (a) Run 3 and (b) Run 5 described in Table 3.

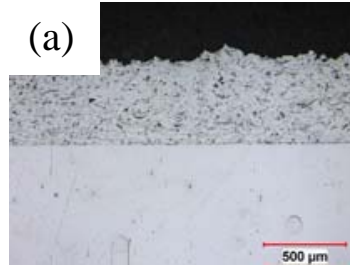

(b)

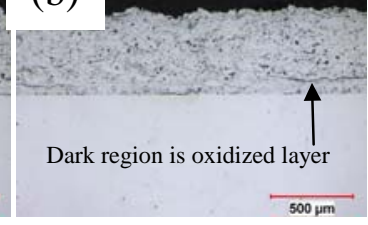

Figure 12. Polished cross sections of LATWA coatings from (a) Run 1 and (b) Run 2 described in Table 3.

mating buttons using high-strength epoxy, and the couple was pulled in tension. In this testing arrangement, coating failure can occur exactly at the substrate/coating interface (this is termed 'adhesive failure') or it can occur within the coating (this is termed “cohesive failure'). In the bond tests performed during this project, the failures were 
predominantly cohesive, which suggests that the interfacial bond strength is even higher. The data points shown in the respective figures are averages of 6-8 measurements.

In Figure 13 the bond test data from the LATWA samples are compared to conventional TWA steel coatings deposited onto steel substrates using nitrogen as the atomizing gas. To help evaluate these data, it is useful to compare several test conditions and view the corresponding substrate/coating interfaces in Figures 11 and 12. For example by decreasing the parameter $d$ from 10 to $5 \mathrm{~mm}$ in going from Run 5 to Run 2, not only is the thin layer of oxide at the substrate interface avoided, their is a concomitant increase in bond strength. While this comparison does illustrate the importance of properly positioning the laser spot relative to the spray pattern, the bond strength achieved with Run 2 is still lower than what is typical for conventional grit blasted TWA coatings. Based on the results from the first 5 runs with 1020 steel wire showing the preference for a short stand-off distance and a higher robot traverse speed, two

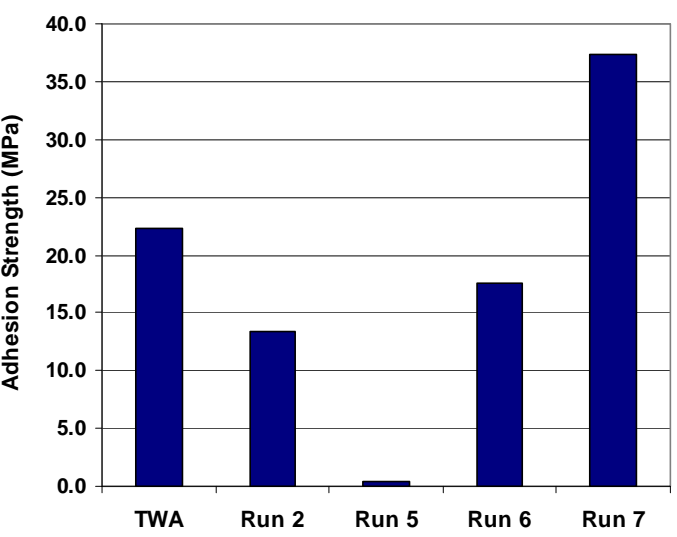

Figure 13. Adhesion strengths of selected LATWA coatings compared to typical value from conventional TWA coatings sprayed using nitrogen. additional runs were performed using wire with a slightly higher carbon content, 1080 steel (Runs 6 and 7). These coating also follow the same trend as the similar 1020 steel coatings, Figure 14 where the tendency for oxidation is decreased as the laser-spray distance, $d$, is decreased. However, also increasing the robot traverse speed along with decreasing $d$ resulted in nearly doubling the bond strength of the 1080 steel coating using the LATWA process.

A series of LATWA trials were performed with 420 stainless steel wires since this material has sufficient hardness for specific wear-related remanufacturing applications. We were not successful in avoiding an oxidized layer at the substrate/coating interface. Figure 15 shows the most successful 420 stainless steel coating, but there is still a thin oxidized layer at the interface; the bond strength of this coating was only $13 \mathrm{MPa}$.

\section{(a)}

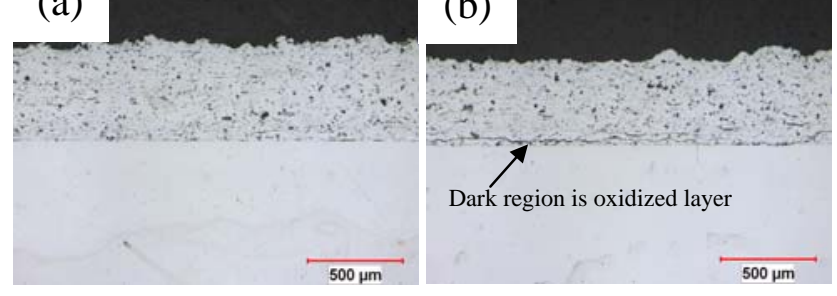

Figure 14. Polished cross sections of 1080 steel LATWA coatings from (a) Run 6 and (b) Run 7 described in Table 3.

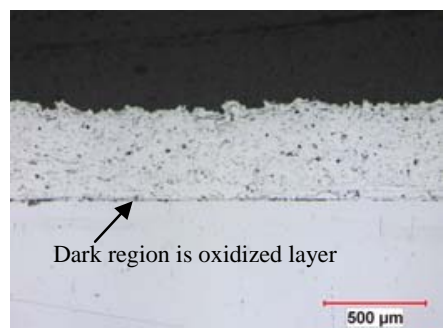

Figure 15. Polished cross sections of a 420 SS LATWA coating using a $290 \mathrm{~mm}$ stand-off distance, $200 \mathrm{~mm} / \mathrm{s}$ traverse speed and $d-10 \mathrm{~mm}$. 
During this project, an effort was focused on attempting to deposit a LATWA coating with the laser operating the entire time. This was aimed at densifying the previously deposited layers. As was seen with the normal LATWA trials, shrouding did not yield any observable differences in the level of oxidation within the throughthickness treated coatings, Figure 16. However, the normal thermal spray splatlike microstructure has been changed by the interaction with the laser, and less porosity is visible. The change in the

(a)

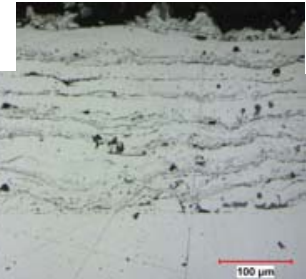

(b)

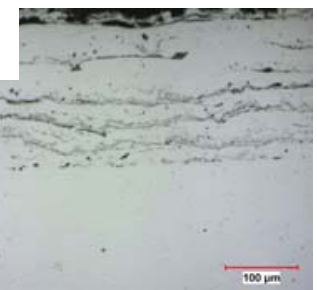

Figure 16. Polished cross sections of throughthickness laser-treated LATWA coatings prepared using (a) shroud shown in Figure 10a and (b) no shroud.

coating microstructure appears to produce an increase in the coating hardness. As seen in Figure 17, the hardness of 1020 steel through-thickness treated coatings is higher than

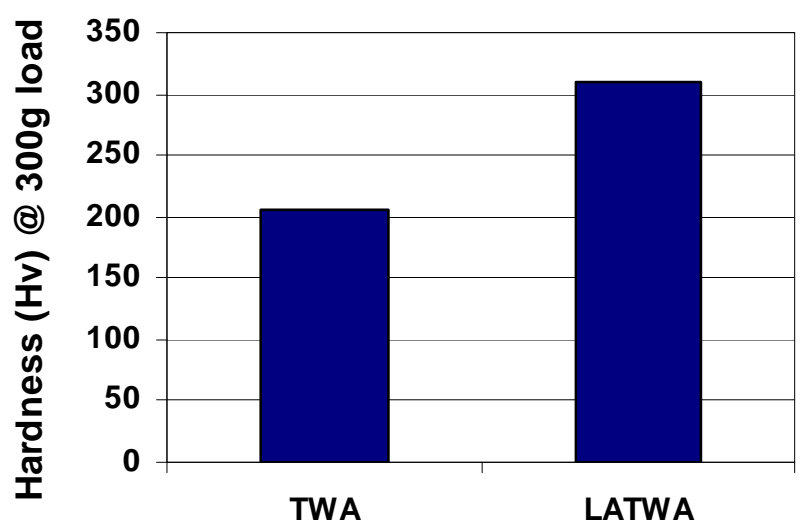

Figure 17. Vickers hardness data from conventional TWA and through-thickness laser-treated LATWA coatings, both using 1020 steel.
1020 steel coatings prepared using conventional TWA methods. It is not clear if the higher hardness is due to a denser microstructure or the presence of localized oxides between the splat layers, Figure 16. The presence of the latter, however, almost certainly will decrease the cohesive strength of the coating, much like what was seen with coatings having a similar oxidized layer at the substrate/coating interface. Accordingly, no further work was directed towards additional attempts to develop through-thickness treated coatings.

The effect of LATWA coating process on the fatigue life was investigated on round bar specimens using a four-point bending fixture, Figure 18. Hard steel and cast iron specimens were used with regard to the possible applications of the LATWA technique to
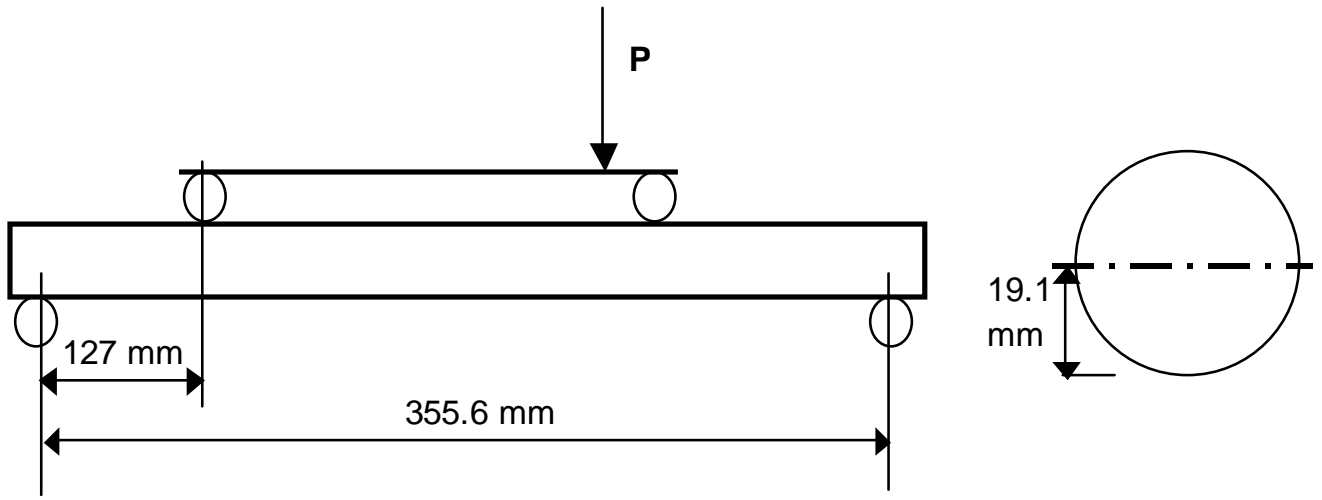

Figure 18. Dimensions of the four point bending fixture and bar specimen 
remanufacture various components. The steel represented components such as crankshafts or cylinders rods, while the cast iron would be applicable to engine blocks and heads. The tests were intended only as an initial evaluation and a more detailed study would need to be conducted on a specific type of material in a real application. The specimens were tested at a single stress level; therefore, the typical S-N curve from a more thorough fatigue study could not be determined. For this work, the primary result from the fatigue test was the condition of the substrate/coating interface around the fracture surface. The LATWA coated specimens were compared to uncoated and conventional TWA coated bars.

All valid test results from the present study are listed in Table 4. The stress level was selected such that the number of cycles to failure was on order of 100 ,. In the case of cast iron, only one valid baseline datum point was acquired, as the remaining baseline cast iron bars ruptured during the first cycle at 351 and $287 \mathrm{MPa}$ stress levels. The results on steel could be compared to the S-N curve of the baseline steel bars and data from other surface treatment techniques that have been collected during prior internal. During that prior work, it was determined that grit blasting, which is a traditional surface preparation technique used before application of thermal spray coatings, lowered the fatigue life approximately ten times at about the same stress levels that were used in the present study, Figure 19. The reduction of the fatigue life was due to the introduction of stress concentrators such as sharp micro notches and/or embedded grit particles. A pulsed q-

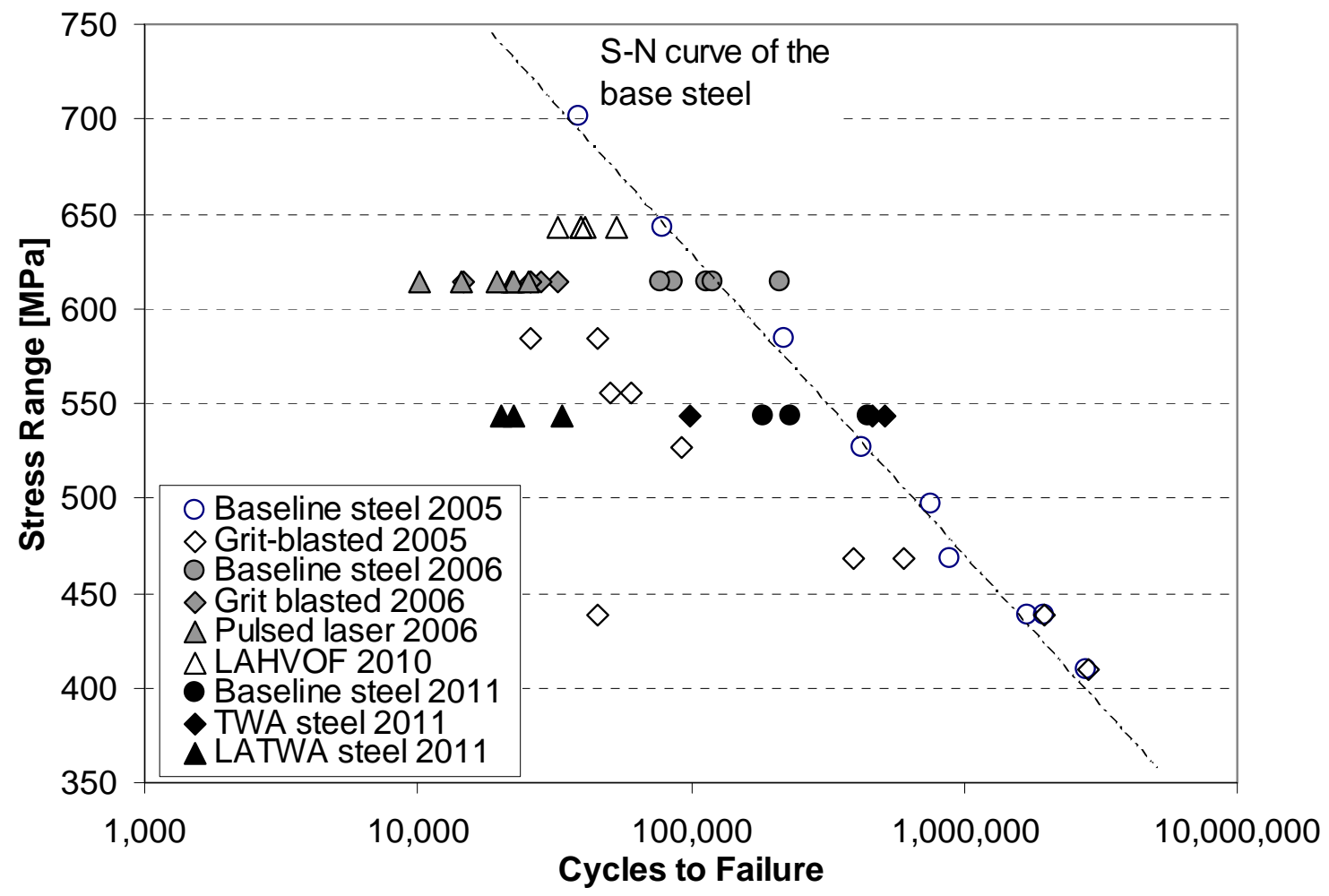

Figure 19. Fatigue life of steel bar specimens compared to internal data from prior work, as identified by 2005-2006 time periods. 
switched type laser used for cleaning appeared to have the same effect. A different prior internal study on the laser-assisted HVOF coating technique indicated that the fatigue penalty was less severe than grit blasting. In the present study, LATWA processing resulted in about ten times fatigue life reduction, which was comparable to the prior data on grit blasting. Moreover, data from the traditional TWA specimens, also manufactured within the present study, overlapped with the data from the baseline polished steel bars. The apparent discrepancy between the prior data on grit blasted steel and the present traditional TWA data might be explained by the differences in the grit blasting parameters and the added stiffness due to the present of the TWA coating. First, the prior data on the effect of grit blasting was acquired from specimens that were treated robotically while the TWA specimens in the present study were grit blasted manually, which might have resulted in a different surface topology. Second, the added thickness of the TWA coating, although having a lower stiffness than a bulk steel, increased the bar stiffness and, therefore, lowered the maximum stress below the nominal value indicated in Table 4.

Table 4 List of fatigue tested samples

\begin{tabular}{|l||l|l|l|l|r|}
\hline Test & $\begin{array}{l}\text { Max Load } \\
\mathrm{kN})\end{array}$ & $\begin{array}{l}\text { Min Load } \\
(\mathrm{kN})\end{array}$ & $\begin{array}{l}\text { Load } \\
\text { Range } \\
{[\mathrm{MPa}]}\end{array}$ & $\begin{array}{l}\text { Frequency } \\
(\mathrm{Hz})\end{array}$ & $\begin{array}{l}\text { Total } \\
\text { Cycles }\end{array}$ \\
\hline Baseline steel & -3 & -96 & 544 & 10.0 & 183,399 \\
\hline Baseline steel & -3 & -96 & 544 & 7.0 & 444,473 \\
\hline Baseline steel & -3 & -96 & 544 & 1.7 & 230,007 \\
\hline TWA steel & -3 & -96 & 544 & 7.0 & 459,329 \\
\hline TWA steel & -3 & -96 & 544 & 7.0 & 99,889 \\
\hline TWA steel & -3 & -96 & 544 & 7.0 & 515,132 \\
\hline LATWA steel & -3 & -96 & 544 & 8.0 & 22,494 \\
\hline LATWA steel & -3 & -96 & 544 & 8.0 & 33,453 \\
\hline LATWA steel & -3 & -96 & 544 & 8.0 & 20,088 \\
\hline Baseline cast iron & -3 & -38 & 205 & 1.7 & 46,804 \\
\hline TWA cast iron & -3 & -41 & 222 & 1.7 & 54,969 \\
\hline TWA cast iron & -3 & -38 & 205 & 1.7 & 92,284 \\
\hline TWA cast iron & -3 & -38 & 205 & 1.3 & 12,682 \\
\hline LATWA cast iron & -3 & -38 & 205 & 8.0 & 1,799 \\
\hline LATWA cast iron & -3 & -38 & 205 & 8.0 & 21,882 \\
\hline LATWA cast iron & -3 & -38 & 205 & 8.0 & 529 \\
\hline
\end{tabular}


LATWA processing of the cast iron specimens lowered the fatigue life on average by about an order of magnitude; however, the scatter of the data was higher compared to the steel specimens, Figure 20. The increased scatter could probably be attributed to several factors such as the more heterogeneous microstructure of the cast iron and variations among the specimens. The fracture surfaces of the cast iron specimens revealed that the bars consisted of "cores" and "cases" that exhibited different textures, Figure 21a. The extent of the core varied within the samples. The outer case appeared to consist of a more nodular graphite and ferrite while the core was more pearlitic with graphite flakes, Figure 22. Also the hardness increased from the case to the core, Figure 23.

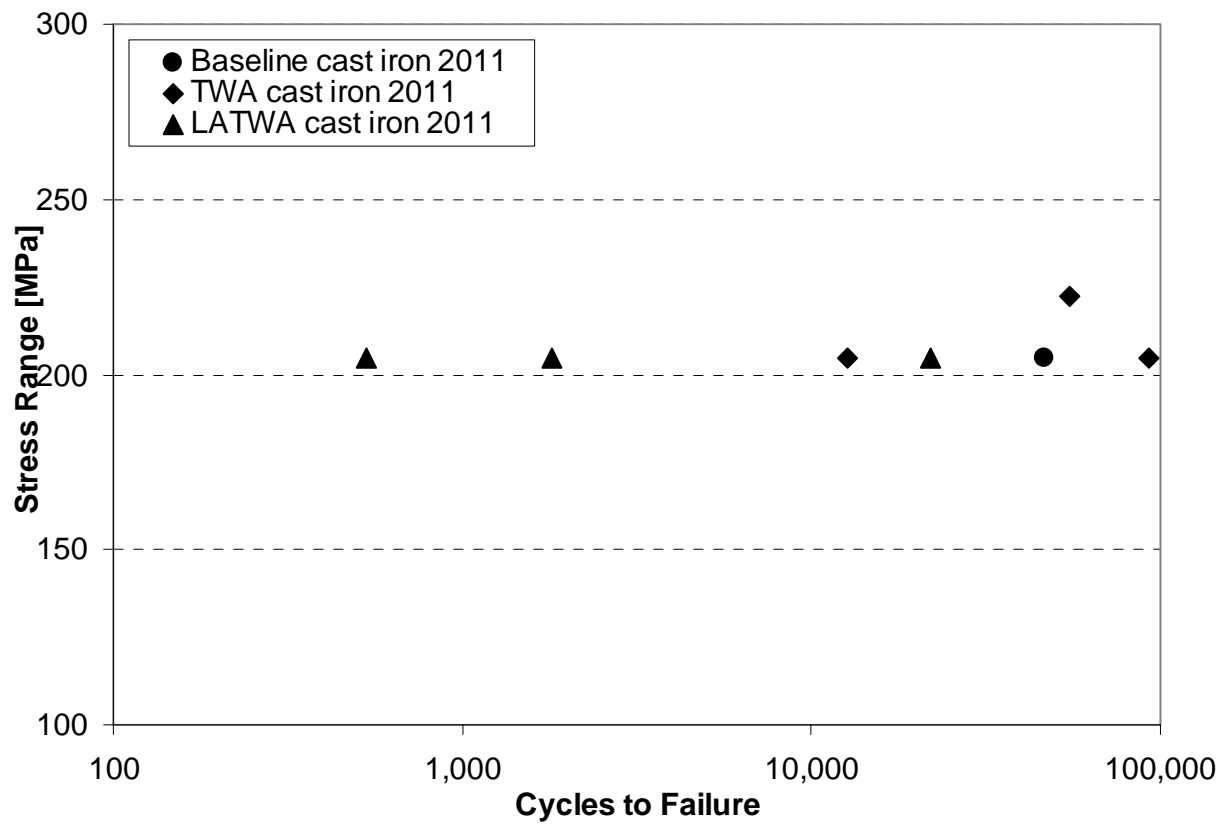

Figure 20. Fatigue life of cast iron specimens.

With the exception of the LATWA coatings on steel, no coatings delaminated in the vicinity of the failure point, Figure 21b. All LATWA coatings exhibit oxide inclusions at the interface between the laser treated initial layer and the conventional topcoat. The LATWA coatings deposited on steel also exhibited oxides at the interface between the substrate and the initial laser-treated layer, although overall the coatings appeared well adhered, Figure 24. The conventional TWA coating on steel clearly exhibited a small gap along the interface on the polished cross sections, Figure 25, further illustrating the improved bonding through the LATWA process. It was not clear why the LATWA coatings on steel were prone to delamination at the point of failure, while the conventional TWA coatings still adhered; however, the LATWA coatings on steel appeared to delaminate along the oxidized interface between the initial laser-treated layer and the topcoat. The LATWA coatings on the cast iron exhibited a clear fusion zone at the interface with the substrate, Figure 26, although the interface between the lasertreated layer and the top coat was oxidized. The conventional TWA coating was well adhered. There was a clear interface between the conventional TWA and the rough surface of the cast iron, but no noticeable separation at the micro scale. 


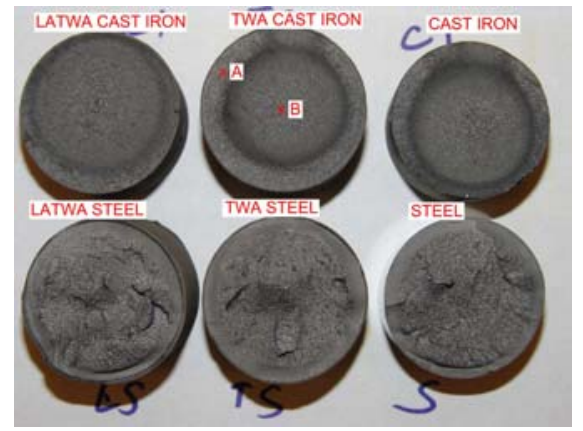

(a)

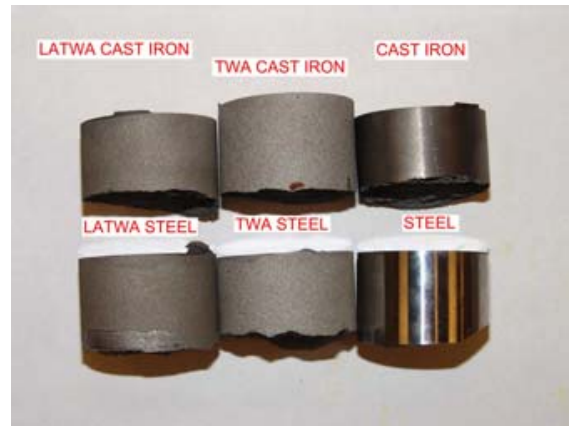

(b)

Figure 21. Cut sections from the failed fatigue tested bars, (a) fracture surface, (b) surface close to the fracture
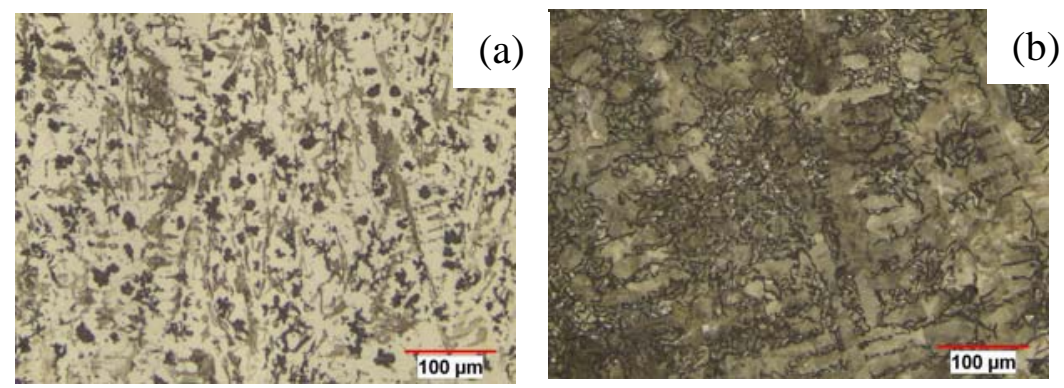

Figure 22 Microstructures of the cast iron bars, (a) in the case and (b) in the core

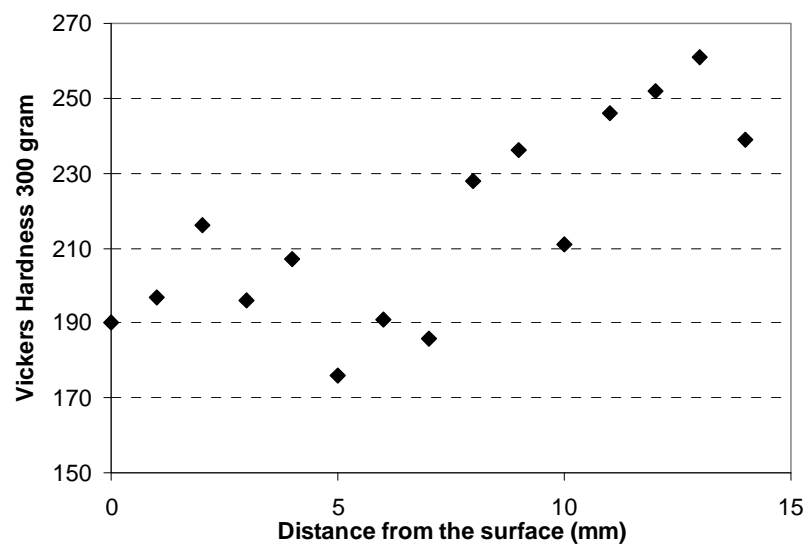

Figure 23 Hardness through the cross section of the cast iron bars. 

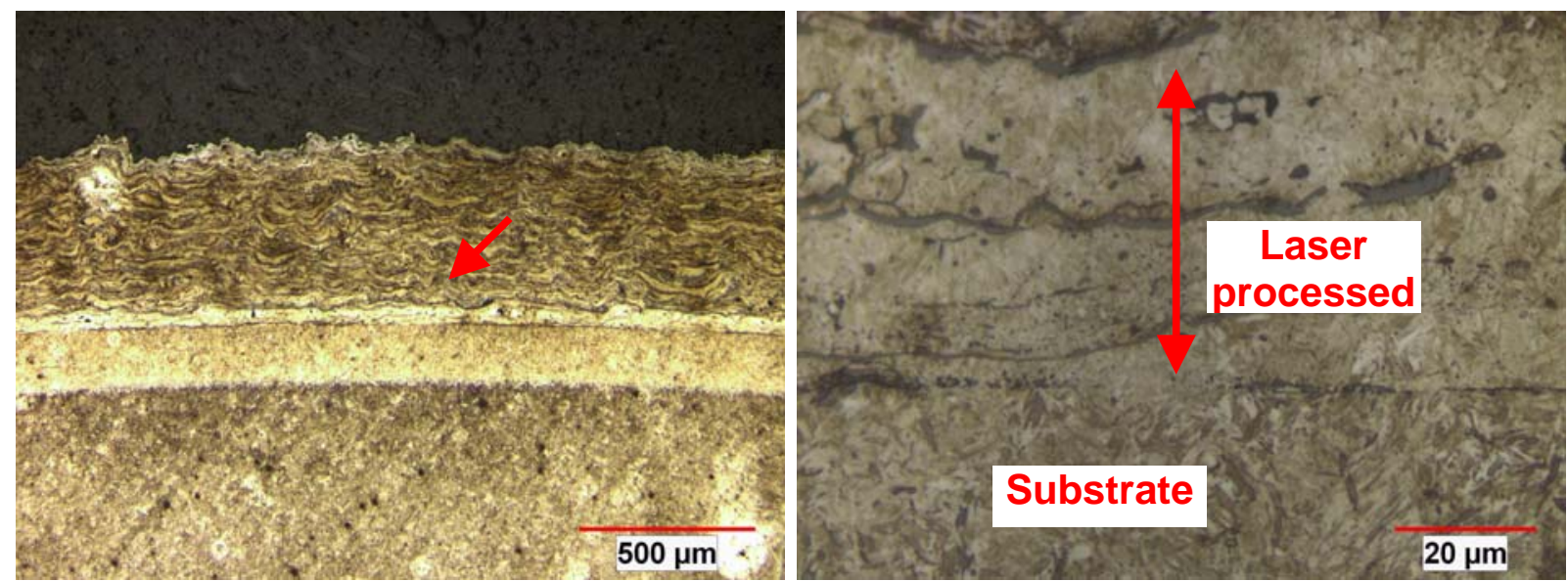

Figure 24. Etched cross section of the LATWA coated steel bar
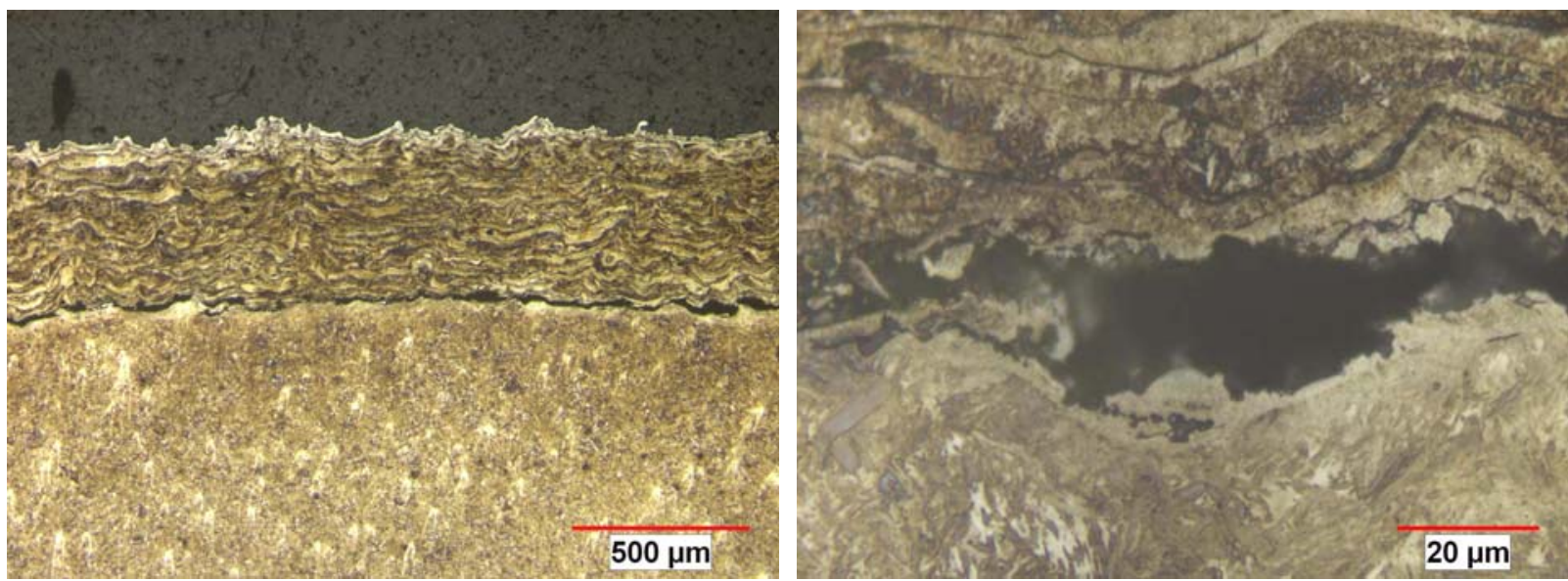

Figure 25 Etched cross section of the conventional TWA coated steel bar.
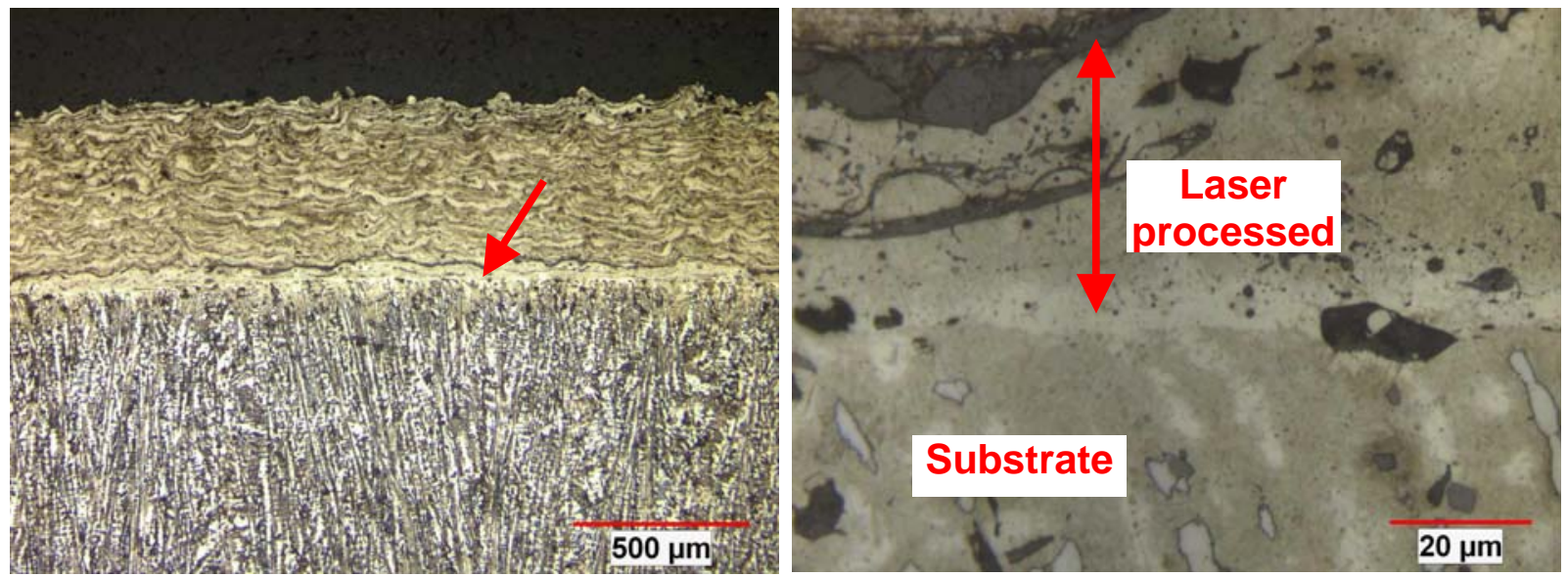

Figure 26 Etched cross section of the LATWA coated cast iron bar 
4.2.2 Al-based Substrates.

At the beginning of this program, the ability to apply hard, strongly bonded coatings to Al-based materials was a very high priority because of the substantial energy savings afforded by remanufacturing Al-based materials. However, as explained below, the LATWA process was not successful in avoiding a thin melted layer at the top surface of the Al-based substrates; the resulting solidified layer was a mixture of hard intermetallic phases that adversely affected the coating bond strength. The Al-based alloys used were 6061 and 2024, the former was selected since it is a ubiquitous structural alloy and the latter because it has some capabilities for welding. The coating material was a Fe29Cr3.8B1.6Si alloy from Nanosteel Corp. This composition is within a family of marginal glass-forming alloys that when rapidly solidified, as in the case of TWA spraying, rapidly nucleate for form a nanocrystalline grain structure. As a consequence of the very fine grain size, these alloys are quite hard ( HRC 68); moreover, the relatively high Cr-content can provide excellent corrosion protection.

For the Al-based alloys the process parameter development approach was similar to that taken for the Fe-based alloys. Two major differences, however, were that $d$ values of 0 and $5 \mathrm{~mm}$ were used in order to intentionally eliminate or reduce the time available for the Al-based surface to oxidize and laser stand-off distances were increased to 310 and $320 \mathrm{~mm}$ in order to increase laser power density. The latter change was made due to the much higher thermal conductivity of Al over steel, which effectively transfers the laser heat more quickly. After surveying a wide range of processing conditions, a fixed set of parameters was selected for further testing, Table 5. In all of the runs listed in Table 5, there were varying degrees of a re-solidified layer at the top surface of the Al-based alloys; there was essentially no noticeable difference between the 6061 and 2024 alloys. To help visualize the type and magnitude of this undesirable layer, Figure 27 displays coatings deposited with a relatively low (Run 5) and a relatively high (Run 9) laser heat input. Both substrate/coating interfaces exhibit a deep heat-affected zone, clearly the higher heat input in Run 9 lead to a deeper zone. Viewing the interface at higher magnification helps to illustrate the coarse, intermetallic grain structure within this heataffected zone. Not surprisingly, the development of this re-solidified layer along with the oxidation at its surface deleteriously impacted the coating adhesions. Bond tests from the samples in Table 5, along with several others from the earlier parameter development work collectively failed to yield bond strengths above $20 \mathrm{MPa}$, and the majority were $<10 \mathrm{MPa}$. Spraying the Fe29Cr3.8B1.6Si alloy onto $6061 \mathrm{Al}$ with conventional grit blast TWA yielded bond strengths averaging $26 \mathrm{MPa}$, which is comparable to 1020 steel deposited by the same method, Figure 13. Because of our inability to avoid the resolidified layer at the surface of all the Al-based substrates, no additional LATWA coated samples were prepared for fatigue testing. 
Table 5 Design of experiments for LATWA coatings onto Al-based substrates

\begin{tabular}{|c|c|c|c|c|}
\hline RUN & Substrate & SOD (mm) & $\begin{array}{c}\text { Speed } \\
(\mathrm{mm} / \mathrm{s})\end{array}$ & $\begin{array}{c}\text { Laser- } \\
\text { Spray d } \\
(\mathrm{mm})\end{array}$ \\
\hline 1 & 6061 & 310 & 140 & 0 \\
\hline 2 & $2024 \& 6061$ & 310 & 200 & 0 \\
\hline 3 & 2024 & 310 & 220 & 0 \\
\hline 4 & $2024 \& 6061$ & 310 & 180 & 0 \\
\hline 5 & 2024 & 310 & 220 & 5 \\
\hline 6 & $2024 \& 6061$ & 310 & 180 & 5 \\
\hline 7 & $2024 \& 6061$ & 320 & 220 & 5 \\
\hline 8 & $2024 \& 6061$ & 320 & 180 & 5 \\
\hline 9 & 2024 & 320 & 180 & 0 \\
\hline 10 & $2024 \& 6061$ & 320 & 220 & 0 \\
\hline
\end{tabular}
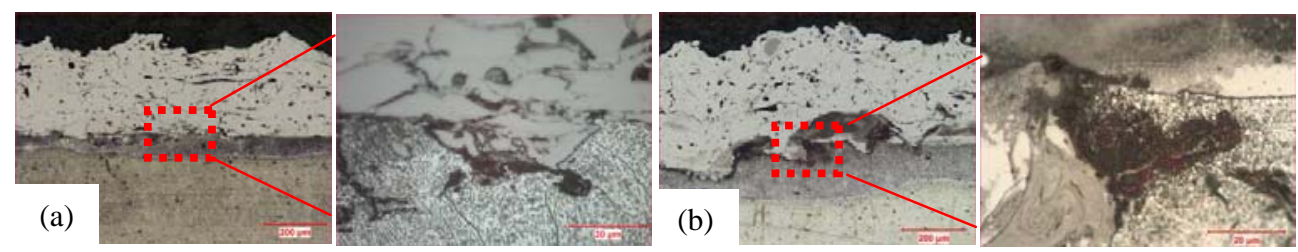

Figure 27. Polished cross sections of LATWA coatings on $2024 \mathrm{Al}$ using (a) low heat input and (b) high heat input conditions. Images on the the right on magnified views of the areas in the red dash lines. 


\section{BENEFITS ASSESSMENT}

To help visualize the energy savings, $\mathrm{CO}_{2}$ reductions and economic benefit that could be realized by successfully developing the LATWA process, several assumptions need to be explained and selected samples need to be put into an appropriate context. To begin, we make a comparison between the energy needed to manufacture a component, and then compare that with the estimated energy required to remanufacture the same component using a specific salvage technology. The associated economic benefit can be envisioned using a similar comparative approach.

\section{i) Energy and $\mathrm{CO}_{2}$ Savings Via LATWA Remanufacturing:}

Utilizing available industrial energy intensities and internal remanufacturing data, energy savings from remanufacturing engine components can be calculated. Data from a review of Industrial Assessment Centers (IACs) concluded the average energy intensity for producing an iron/steel casting was roughly $4450 \mathrm{BTU}-\mathrm{hr} / \mathrm{lb}$ and a forging was roughly $5970 \mathrm{Btu}-\mathrm{hr} / \mathrm{lb}$ [1]. Furthermore, when a good core (i.e., part to be remanufactured requires minimal processing beyond the intended steps) is available, a typical high volume crankshaft can be remanufactured with a 96\% energy savings compared to the original manufacturing process [2]. However, this is more of an ideal case, and in light of the more industry-wide accepted estimated energy savings of $85 \%$, the scenario discussed below illustrating energy and GHG reductions utilized an estimated average energy savings of $90 \%$. An in-house estimate of $3.8 \times 10^{-4} \mathrm{lbs} \mathrm{CO}_{2} / \mathrm{Btu}$ was generated during the analysis of metal-processing manufacturing. As a comparison, Daniels [3] claims that his estimate of 400 trillion Btu's per year of energy savings through remanufacturing avoids the generation of 28 million tons of $\mathrm{CO}_{2}$, which is equivalent to $1.4 \times 10^{-4} \mathrm{lbs}_{\mathrm{CO}_{2} / \mathrm{BTU}}$ and is reasonably close to the estimate generated by Daniels et al. [2].

For the comparative analysis shown below, two different metal processing routes were considered, castings and forgings, and the prototypical components for each process were liners and crankshafts, respectively. The quantities of parts used in the analysis are based on our internal production of approximately 158,000 diesel engines in 2007. This leads to roughly 1,000,000 liners (assuming a mixture of 6- and 8-cylinder engines) and 158,000 crankshafts. Using the abovementioned energy intensity factors for casting and forgings, respectively, of 4450 and $5970 \mathrm{Btu}-\mathrm{hr} / \mathrm{lb}$ [1] along with the energy-induced $\mathrm{CO}_{2}$

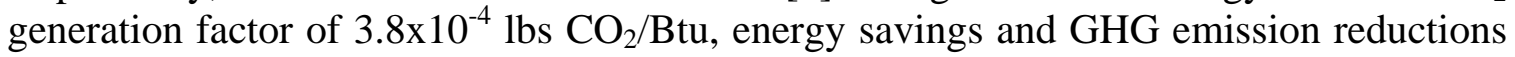
listed in the table below were obtained.

Table 1. Estimates of Energy Savings and $\mathrm{CO} 2$ Reductions by Remanufacturing

\begin{tabular}{|l|l|l|l|l|l|}
\hline & $\begin{array}{l}\text { Quantity } \\
\text { in 2007 }\end{array}$ & $\begin{array}{l}\text { Manufacturing } \\
\text { method }\end{array}$ & $\begin{array}{l}\text { Energy } \\
\text { Intensity } \\
\text { Factor } \\
\text { (BTU-hr/b) }\end{array}$ & $\begin{array}{l}\text { Annual Energy } \\
\text { Savings By } \\
\text { Remanufactring } \\
\text { (BTU) }\end{array}$ & $\begin{array}{l}\text { Annual } \mathrm{CO}_{2} \\
\text { Reductions By } \\
\text { Remanufacturing } \\
\text { (lbs) }\end{array}$ \\
\hline Crankshaft & 156,000 & Forging & 4450 & $8.8 \times 10^{12}$ & $3.3 \times 10^{6}$ \\
\hline $\begin{array}{l}\text { Engine } \\
\text { Liner }\end{array}$ & $1,000,000$ & Casting & 5970 & $8.4 \times 10^{12}$ & $3.2 \times 10^{6}$ \\
\hline
\end{tabular}


It is critical to note that the comparative energy and $\mathrm{CO}_{2}$ savings numbers above only reflect the manufacturing and remanufacturing estimated discussed above, and do not include the energy and GHG emissions that result from the actual remanufacturing process. Energy intensity factors are not known for thermal spray processes such as twinwire arc spraying. So to help make a rough comparison, twin-wire arc spraying of 420 stainless steel onto crankshaft journals and the o.d. surfaces of engine liner will be explored. For a 6-cylinder crankshaft, the surface area of the journals is approximately $0.08 \mathrm{~m}^{2}$, which fortuitously compares closely to the surface area of a $0.2 \mathrm{~m}$ dia. by $0.4 \mathrm{~m}$ tall engine liner. Consequently, a surface area of $0.08 \mathrm{~m}^{2}$ will be used along with a typical coating thickness for surface restoration of $0.02 \mathrm{~m}$ can be used to estimate $0.0016 \mathrm{~m} 3 \mathrm{as}$ the volume of coating employed to salvage one crankshaft or one cylinder liner. The normal spray rate for 420 stainless steel is $8 \mathrm{~kg} / \mathrm{hr}$, which leads to a total spray time for one crankshaft or one liner of approximately 15 minutes. Equipment manufacturers often report that twin-wire arc spraying consumes $6 \mathrm{KW} / \mathrm{hr}$ (equivalent to 20, $500 \mathrm{BTU}$ ); therefore, one crankshaft or one liner will consume around 5125 BTU. These energy consumption estimates are about 1000 times lower (on a per piece basis) than the energy savings displayed above, and accordingly illustrate the rather minor impact in overall energy savings by the power consumption of the twin-wire arc spray remanufacturing process. Even if the laser power contribution is considered for the LATWA process, which is $2-30 \%$ of the twin-wire arc electricity consumption, based on the duration of time the laser is used, the overall energy footprint of the remanufacturing process is extremely small compared to the energy savings afforded by avoiding the manufacturing of a new part. Considering other steel diesel engine components including cylinder heads, connecting rods and camshafts readily increases the above estimates.

\section{ii) Cost Savings via LATWA Remanufacturing:}

The economic benefit of using LATWA to salvage a component may be estimated in much the same way as the energy benefits were assessed above. For example, a new cast iron engine liner has a new part cost between $\$ 40-60$. The cost to deposit the $0.08 \mathrm{~m}^{3}$ of 420 stainless steel using LATWA includes materials, electrical, air, labor and consumables for the process as well as the costs for machining to remove damaged material prior to coating and final machining of the deposited coatings. Note that the approximate cost of 420 stainless steel wire is $\$ 5 / \mathrm{lb}$, and the price of other stainless (e.g., 300 -series) and low-carbon steels are generally within $10-25 \%$ of this price. As a consequence, these small changes in material costs have a very small effect on the overall coating cost. It is difficult to put precise estimates on some of the contributing costs, but using commonly accepted numbers for labor and electricity, one liner would cost around $\$ 30$ to fully salvage using LATWA. This is not a particularly compelling value compared the new part costs that are roughly double. However, extending this $\sim \$ 20 /$ part remanufacturing cost over the nearly 1,000,000 liners produced internally in 2007 helps to illustrate the magnitude accessible for even a marginally attractive remanufacturing opportunity. The economic situation becomes far more appealing when more expensive components like crankshafts, which can cost \$300-500 each, are considered.

An alternate approach to examining the potential cost savings of LATWA is to compare the process cost to another thermal spray technique that LATWA could conceivably replace. The obvious candidate for replacement is High-Velocity Oxygen-Fuel (HVOF) 
spraying, which provides denser, stronger coatings compared to conventional twin-wire arch spraying, but at a higher price. There are numerous routes to estimating the cost of various thermal spray processes, but all these routes must consider a core set of variables. The typical way of comparing the costs of various components is to generate a price to coat a certain area dimension at a specific coating thickness. While this is of course simply a volume, presenting in these terms yields some commonality among normal coating thicknesses and allows one to visualize a surface area that has more physical meaning. An in-house assessment of thermal spray costs yielded the following costs for a $930 \mathrm{~cm}^{2}$ coating at a thickness of $0.06 \mathrm{~cm}\left(1 \mathrm{ft}^{2}\right.$ coating at a thickness of 0.025 ”).

Twin-wire arc

HVOF (propylene gas fuel)

HVOF (liquid kerosene fuel)
$\$ 161$

$\$ 280$

$\$ 560$

The rather significant difference between the two HVOF process is largely related to consumables, and these details our beyond the scope of this comparison. Regardless of the HVOF process used in the comparison, it is evident that twin-wire arc spraying is cheaper. By incorporating a laser to run the LATWA process, the $\$ 161$ estimate increases by $\sim 2-30 \%$, again depending on the time the laser is active during the spray process. This still reveals that LATWA can offer a cost savings over HVOF spraying. In addition, the capital cost of HVOF equipment can be 5-10X that of twin-wire arc. The cost of a laser, of course, represents a capital expenditure; however, the cost of a laser is comparable to a robotically-controlled grit blasting system with a dust collection system. If a laserassisted process is employed, then a grit blasting system is not required.

\section{References:}

[1] United States Department of Energy - Industry Assessment Centers (USDOE-IAC), 2007, "IAC Database."

[2] D. P. Adler et al., "Comparing Energy and Other Measures of Environmental Performance in the Original Manufacturing and Remanufacturing of Engine Components," Proceedings of the 2007 International Manufacturing Science And Engineering Conference - manuscript number MSEC2007-31220, (2007).

[3] E. Daniels, "A Roadmap for Recycling End-of-use Vehicles of the Future," USDOE Office of Advanced Automotive Technologies, Argonne National Laboratory, May 2001. 


\section{COMMERCIALIZATION}

The capability to significantly increase the bond strength with ferrous substrates and coatings may open new remanufacturing opportunities that were previously not considered due to concerns with the limits of the mechanical bonding of conventional TWA coatings. However, the limited results obtained within this one-year program are not sufficient to move the LATWA into a production environment. Additional work will be needed engineer the process to coat components with more complex geometries than the flat specimens studied in this work. In addition part-specific bench testing and relevant field tests will be required to fully establish the necessary confidence for introducing the LATWA process. These are typical constraints and requirements for most any new production process, and it is quite possible this new process will continue to be a viable approach for extending the usage of remanufacturing, and in turn capturing the resulting energy savings and green house gas emission reductions.

It appears that oxidation at the substrate/coating interface is the primary challenge to overcome in order to obtain a dense diffusion-type bond that provides significantly improved bond strength. Optimal parameters will be dependent on both the substrate and coating materials; therefore, the path forward for bringing the LATWA process closer to commercialization will benefit from a judicious selection of a small number of targeted applications having components with the same composition and requiring the same type of coating material. This will help reduce the amount of development time and effort, and also allow for the incorporation of the needed work to develop parameters for coating complex surfaces (e.g., crankshaft bearing journals and turbochargers).

\section{ACCOMPLISHMENTS}

The only notable outside accomplishments from this project are the presentation at and manuscript submission to the Materials Science \& Technology 2011 conference in Columbus, OH. Dr. Ondrej Racek delivered the presentation and he along with Dr. Daniel Sordelet were the authors on the submitted manuscript. 


\section{CONCLUSION}

The feasibility of coupling a laser with a traditional twin-wire arc (TWA) thermal spray system to form a surface coating that is diffusionally bonded to the substrate and exhibits increase bond strength was successfully demonstrated. This hybrid process is referred to as laser-assisted twin-wire arc (LATWA) spraying. During this one-year performance period, we were able to identify the critical processing parameters that controlled the quality of the coating bond at the substrate interface. We found that it was imperative to avoid or at least minimize oxidation of both the substrate and the initially deposited coating layer in order to prevent full coating delamination or reduce bond strength. The important process parameters include the speed of the laser and torch across the substrate surface, the distance that the laser spot leads the incoming spray droplets and the power density of the laser. Properly adjusting these conditions led to an apparently oxide-free substrate/coating interface and bond strengths that were $~ 50 \%$ higher than the same coating deposited with normal TWA spraying techniques. These results, however, were only observed with mild steel coatings (1080 steel) on 4140 steel substrates. Other steels like 420 stainless steel had a higher tendency to oxidize and showed lower bond strength. A series of trials were conducted with Al-based substrates, but all the processing condition examined resulted melting a thin layer on the substrate surface, which subsequently produced a re-solidified boundary with brittle intermetallics, yielding poor bond strengths.

Remanufacturing as an industrial process continues to be a tremendous opportunity for achieving substantial energy savings and green house gas emission reductions. The motivation for this project was to help demonstrate the feasibility of a surface coating salvage technique for components that are currently not candidates for coating restoration either due to performance (i.e., the conventional TWA mechanical bond is not sufficient) or cost. The LATWA process is one approach that can help to expand the amount of remanufacturing, thereby saving energy and reducing $\mathrm{CO}_{2}$ by avoiding the fabrication of new components. Beyond our internal interest to pursue technologies like the LATWA process for remanufacturing applications, other communities are recognizing the beneficial global environmental benefit of restoring surfaces to achieve multiple lifetimes for metallic components. In particular, a multidisciplinary team charged by the DOE Industrial Technologies Program identified surface treatment process for life extension as a high-priority process innovation needed for the national goals of energy and $\mathrm{CO}_{2}$ reductions. Hopefully efforts like this will help to catalyze new surface engineering approaches that will facilitate additional opportunities for remanufacturing processes. 